\title{
CAPILLARY ELECTROPHORESIS AS A VERIFICATION TOOL FOR IMMUNOCHEMICAL DRUG SCREENING
}

\author{
Joanna Znaleziona ${ }^{a *}$, Jan Petra, Vitezslav Maier ${ }^{\mathrm{a}}$, Radim Knob ${ }^{\mathrm{a}}$, Jana Horakova ${ }^{\mathrm{a}}$, \\ Dana Smetanova ${ }^{\mathrm{a}}$, Juraj Sevcik ${ }^{\mathrm{a}}$
}

\author{
a Department of Analytical Chemistry, Faculty of Science, Palacky University, tr. Svobody 8, CZ-771 46 Olomouc, Czech \\ Republic
}

Received: February 25, 2007; Accepted: April 4, 2007

Key words: Capillary electrophoresis/Drug abuse/Toxicological screening/Immunochemical analysis/Clinical toxicology

\section{+ Dedicated to Bretislav Smysl in memoriam}

Background: The aim of this work was to develop a simple capillary electrophoretic method as the verification and confirmation tool in the screening analysis for amphetamines, opiates, benzodiazepines and cocaine and their metabolites for toxicological applications.

Methods: $50 \mathrm{mM}$ phosphate Tris pH 2.0 with $30 \%(\mathrm{v} / \mathrm{v})$ of methanol was used as a background electrolyte that enabled fast separation of drugs and their metabolites in saliva and urine. Verification of the data from the electrophoretic method was done by High Performance Thin Layer Chromatography (HPTLC) and the immunochemical screening test QuikScreen.

Results: The experimental conditions of the Capillary Electrophoresis (CE) were partially optimized (mainly the influence of concentration and types of additives, e.g. cyclodextrines, organic solvents) and validated; the method was used for analysing samples from drug abusers.

Conclusions: The non-instrumental, immunoassay tests could only confirm qualitative addictions and are mainly employed when the emergency detection of drugs is needed. For quantitative analysis and verification of obtained results the confirmation step is strongly recommended. The simple screening capillary zone electrophoresis method allows recognition of the most abused drugs. The agreement of the results from CE, HPTLC and QuikScreen test was more than $95 \%$.

\section{INTRODUCTION}

These days the misuse of addictive drugs has become very widespread especially in certain professions and groups of people such as the military, police, professional drivers, managers, teachers and students. Therefore a new broader range of drug screening has been researched and developed ${ }^{1}$. These screenings are usually done at drop-in centres, police and certified laboratories using immunochemical one-step tests ${ }^{2,3}$. These simple tests determine common drugs in small sample volumes (saliva, urine, plasma, serum, etc.) and can be applied directly, anywhere outside the laboratory. However positive results of immunochemical screening of abused drugs in biofluids must be verified by another independent and sophisticated analytical method. Hyphenation techniques that include extraction and sample concentration (L-L extraction, SPE, SPME); high performance separation (HPLC, GC) and mass spectrometric detection are commonly used for detection and identification of drugs and their metabolites $^{4-9}$.

Capillary electrophoresis (CE) can be an alternative efficient technique which is characterized by high separation efficiency and selectivity, high sample throughput, small sample consumption, resistance, simple instrumentation, etc. ${ }^{10-13}$. All CE modes employ the same instrumentation; samples can be easily analyzed subsequently as differencing separation mechanisms. Generally, CE is a very promising tool for clinical analysis at the present time ${ }^{14-19}$ and it could be a simple and less time-consuming alternative technique to HPLC and GC which are also based on different separation mechanisms than $\mathrm{CE}$. The selectivity of CE can be utilized for separation of complicated mixtures of target analytes (e.g. abused drugs, diagnostic markers, etc.) from matrix without multistep sample preparation. Moreover CE is a highly effective technique for chiral separations of drugs using many types of chiral electrolyte additives (cyclodextrins, crown-ethers, chiral surfactants, macrocyclic antibiotics, glycopeptides, etc.) which give $\mathrm{CE}$ a very large potential for studying the metabolism of chiral and non-chiral drugs ${ }^{20-22}$.

A number of studies on toxicological screening and monitoring of abused drugs by $\mathrm{CE}$ techniques have been published over the past ten years ${ }^{23-26}$. These contributions discuss problems with the sample preparation of drugs in biofluids (such as urine, blood, plasma, serum) for CE separation and the ability of CE methods to screen various types of abused drugs. Unfortunately the majority of 
Table 1. Method validation.

\begin{tabular}{|l|c|c|c|c|}
\hline \multirow{2}{*}{ Compound } & \multicolumn{2}{|c|}{ Repeatability of migration times } & Tested linear calibra- \\
\cline { 2 - 5 } & $\begin{array}{c}\text { Intraday, } \\
\text { RSD (\%) }\end{array}$ & $\begin{array}{c}\text { Interday, } \\
\text { RSD }(\%)\end{array}$ & $\begin{array}{c}\text { Limit of detection } \\
(\mu \mathrm{g} / \mathrm{mL})\end{array}$ \\
\hline AMP (1) & 0.2 & 7.3 & $2.0-100.0$ & 1.5 \\
\hline MET (2) & 0.3 & 8.1 & $2.0-100.0$ & 2.1 \\
\hline cocaine (3) & 0.5 & 8.3 & $5.0-100.0$ & 2.4 \\
\hline codeine (4) & 0.8 & 11.7 & $5.0-50.0$ & 2.5 \\
\hline MOR (5) & 1.2 & 11.8 & $5.0-50.0$ & 2.5 \\
\hline ETM (6) & 1.2 & 12.3 & $5.0-50.0$ & 2.8 \\
\hline MAM (7) & 1.3 & 11.5 & $5.0-50.0$ & 2.8 \\
\hline DAM (8) & 1.3 & 13.2 & $5.0-50.0$ & 1.6 \\
\hline 7-AF (9) & 0.8 & 11.7 & $5.0-100.0$ & 1.4 \\
\hline diazepam (10) & 0.7 & 12.5 & $5.0-100.0$ & 1.6 \\
\hline BLN (11) & 0.9 & 10.8 & $5.0-100.0$ & 1.8 \\
\hline FNAP (12) & 0.9 & 11.4 & $5.0-100.0$ & 1.9 \\
\hline ACBP (13) & 1.0 & 12.9 & $5.0-100.0$ & \\
\hline
\end{tabular}

Intraday precision for 3 days; average RSD values for intraday precision are shown; linear calibrations were made with 6 points (each with 5 repetitions).

AMP, amphetamine; MET, methamphetamine; MOR, morphine; ETM, ethylmorphine; MAM, 6-monoacetyl-morphine; DAM, diacetylmorphine; 7-AF, 7-aminoflunitrazepam; BLN, benzoyleckognine; FNAP, flunitrazepam; ACBP, 2-aminochlor-benzophenone

Table 2. Results from immunochemical tests and CE and HPTLC methods.

\begin{tabular}{|c|c|c|c|c|c|c|}
\hline \multirow{2}{*}{$\begin{array}{c}\text { Sample } \\
\text { No. }\end{array}$} & \multicolumn{4}{|c|}{ Imunochemical tests* } & \multirow{2}{*}{ HPTLC ** } & \multirow{2}{*}{$\mathrm{CE}^{* *}$} \\
\hline & AMP & MET & OPI & BZD & & \\
\hline 1 & pos/neg & pos & neg & pos & MET, 7-AF & MET, 7-AF \\
\hline 2 & neg & neg & pos & neg & ETM, MOR & ETM, MOR \\
\hline 3 & pos & pos & neg & neg & MET, AMP & MET, AMP \\
\hline 4 & neg & neg & pos & pos & MOR, 7-AF & MOR, 7-AF \\
\hline 5 & neg & neg & neg & pos & 7-AF & 7-AF \\
\hline 6 & pos & pos & pos & neg & MET, AMP, MOR & MET, AMP, MOR \\
\hline 7 & pos/neg & pos & neg & neg & MET & MET \\
\hline 8 & neg & neg & pos & neg & MOR & MOR \\
\hline 9 & neg & neg & neg & pos & 7-AF & 7-AF \\
\hline 10 & pos & pos & neg & neg & MET, AMP & MET, AMP \\
\hline 11 & neg & neg & pos & pos & ETM, MOR, 7-AF & ETM, MOR, 7-AF \\
\hline 12 & pos & pos & neg & neg & MET, AMP & MET, AMP \\
\hline
\end{tabular}

*AMP = amphetamines; MET = methamphetamines; OPI = opiates; $\mathrm{BZD}=$ benzodiazepines; pos = the test was positive; neg = the test was negative

** MET = methamphetamin; AMP = amphetamin; MOR = morphine; $\mathrm{ETM}=$ ethylmorphine; 7 -AF = 7-aminoflunitrazepam 


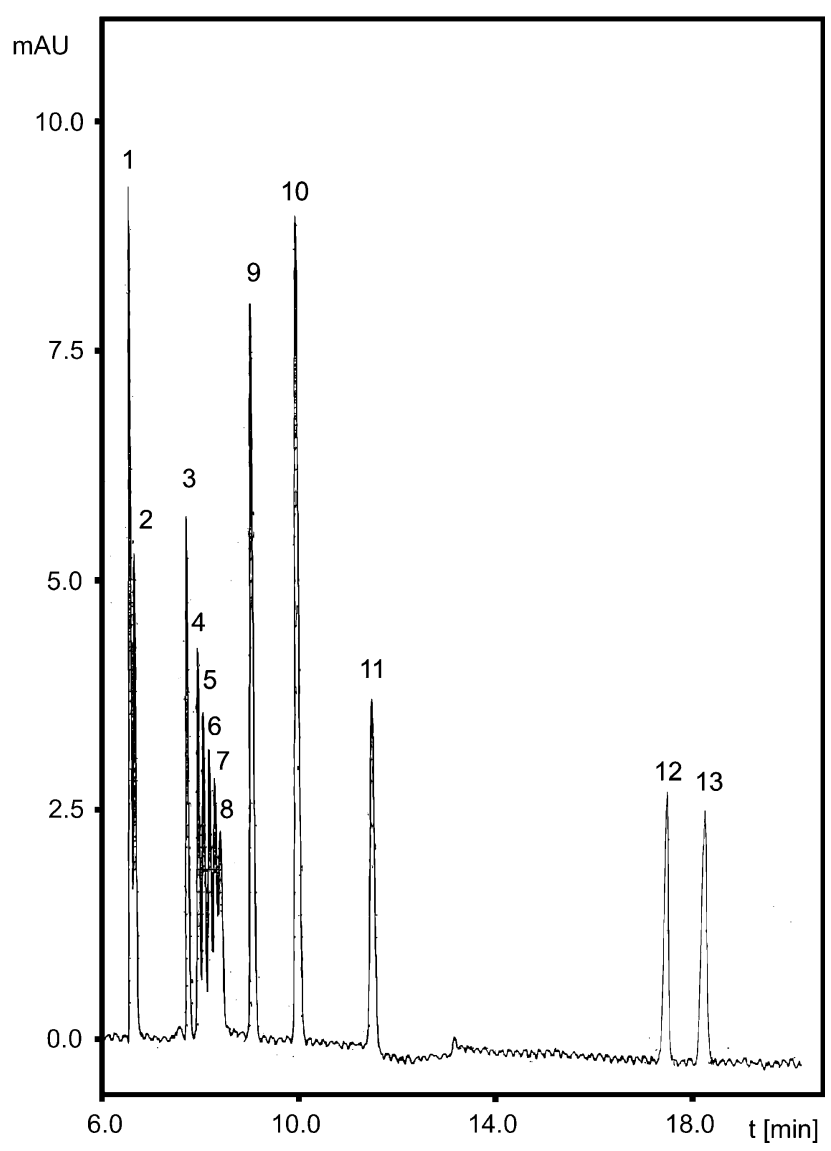

Fig. 1. Electropherogram of standard mixture of groups of abused drugs

BGE $50 \mathrm{mM}$ phosphate-Tris buffer $\mathrm{pH} 2.0$ with $30 \%(\mathrm{v} / \mathrm{v})$ of methanol.

Separation voltage $30 \mathrm{kV}$; concentration of standard mixture $10^{-4}$ mol. $\mathrm{L}^{-1}$.

1: amphetamine (AMP), 2: methamphetamine (MET), 3: cocaine, 4: codeine, 5: morphine (MOR), 6: ethylmorphine (ETM), 7: 6-monoacetyl-morphine, 8. diacetylmorphine, 9: 7-aminoflunitrazepam (7-AF), 10: diazepam, 11: benzoyleckognine, 12: flunitrazepam, 13: 2-aminochlor-benzophenone

published papers are focused on only one type of drug (e.g. opiates, amphetamines, benzodiazepines, antidepressant drugs).

The aim of this work was to develop a simple capillary electrophoretic method as the verification and confirmation tool for screening analysis of amphetamines, opiates, benzodiazepines, cocaine and their metabolites, for toxicological application. The developed method was applied to real samples of saliva and urine, which were collected from addicts in the Czech Republic. The results obtained from CE analysis were compared with the HPTLC method and with the multicomponent immunochemical test used for toxicological screenings.

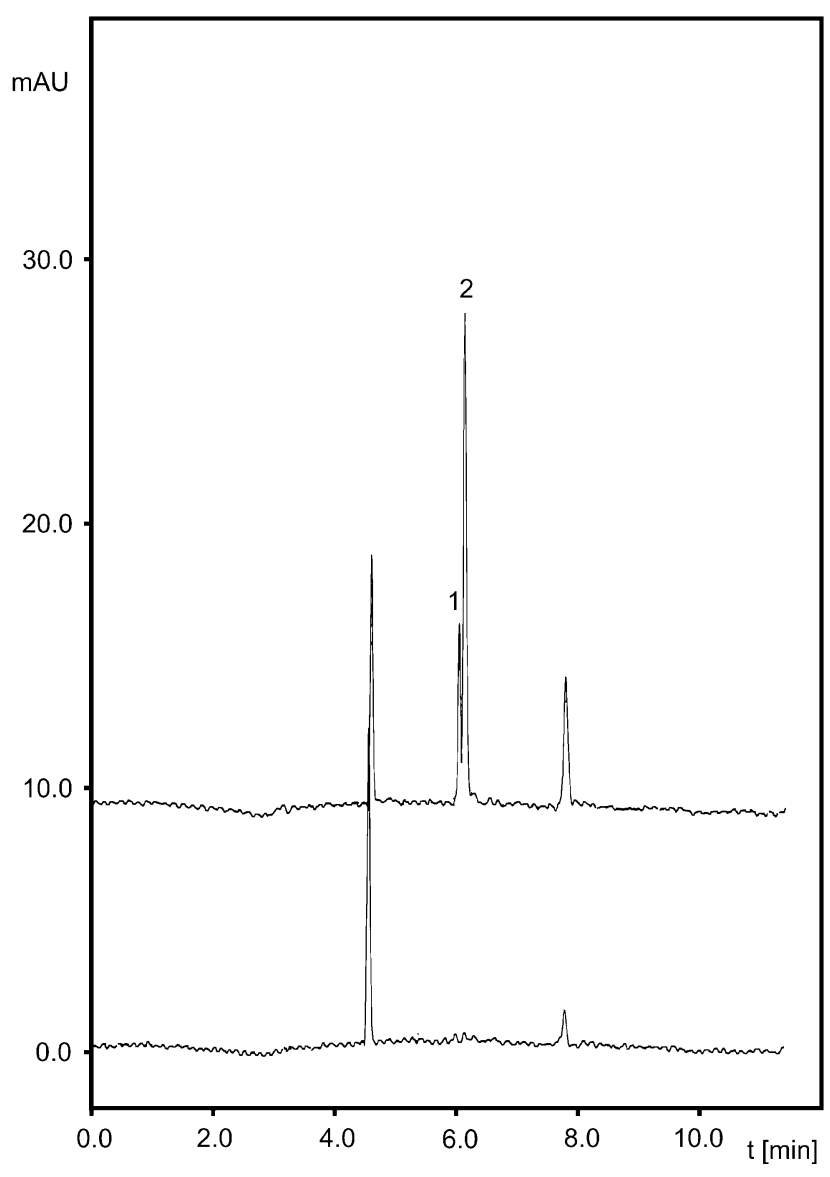

Fig. 2. Electropherograms of saliva extract from volunteer after methamphetamine dosage.

BGE $50 \mathrm{mM}$ phosphate-Tris buffer pH 2.0 with $30 \%$ (v/v) of methanol; separation voltage $30 \mathrm{kV}$. Top electropherogram presents sample after 24 hours after dosage. Lower electropherogram corresponds to sample immediately after dosage.

1: amphetamine, 2: methamphetamine

\section{MATERIALS AND METHODS}

\section{Chemicals}

Phosphoric acid, tris(hydroxymethyl)aminomethane (Tris), sodium hydroxide, methanol and ethyl acetate were obtained from Sigma (St. Louis, USA). All of chemicals were analytical grade quality. Drugs and its main metabolites were kindly provided from the Institute of Forensic Medicine and Medical Law, Palacký University, Olomouc, Czech Republic. Biological samples were collected from drug addicts (narcomaniacs) in cooperation with the Drop-in Centre Olomouc. Deionised water (Elga, Bucks, England, $18 \mathrm{M} \Omega . \mathrm{cm}^{-1}$ ) was used for preparation of all solutions. 


\section{Apparatus and conditions}

The separations were performed on the capillary electrophoresis SpectraPHORESIS 100 with fast-scanning UV/VIS detector SpectraFOCUS (Thermo Separation Products). Uncoated fused silica capillaries (CACO-Silica Tubing and Optical Fibers, Slovakia) of total and effective lengths of $75 \mathrm{~cm}$ and $45 \mathrm{~cm}$, respectively, $75 \mu \mathrm{m}$ I.D. x 365 $\mu \mathrm{m}$ O.D. were used for these experiments. The capillary was thermostated at $25^{\circ} \mathrm{C}$, the applied voltage was $+30 \mathrm{kV}$ $\left(+400\right.$ V.cm $\left.{ }^{-1}\right)$. Statistical evaluations were done using the data analysis programme QC Expert 2.5 (TriloByte Statistical Software, Pardubice, Czech Republic). The background electrolyte was prepared by diluting an appropriate amount of phosphoric acid in deionised water and then the solution was titrated with Tris to $\mathrm{pH} 2.0$; finally methanol was added to the background electrolyte. Drugs and their metabolites were dissolved in a ten times diluted background electrolyte. Samples were injected for $0.5 \mathrm{~s}$ by vacuum. The capillary was washed daily before the first experiment with 0.1 mol.L $\mathrm{L}^{-1} \mathrm{NaOH}$ solution for $10 \mathrm{~min}$, then with water (10 min); 0.1 mol. $\mathrm{L}^{-1} \mathrm{HCl}$ (10 min); again with water ( $10 \mathrm{~min})$; and finally with the working electrolyte for $15 \mathrm{~min}$. The capillary was washed with BGE between individual analysing runs. All measurements were executed five times.

\section{Comparative screening assays}

The multicomponent immunochemical QuikScreen ${ }^{\mathrm{TM}}$ tests (donated by Exbio, Olomouc, Czech Republic) were used for comparison of results obtained by the $\mathrm{CE}$ method. The test was utilized for amphetamine (sensitivity $1.0 \mu \mathrm{g} / \mathrm{mL})$, benzodiazepines $(0.3 \mu \mathrm{g} / \mathrm{mL})$, methamphetamine $(1.0 \mu \mathrm{g} / \mathrm{mL})$, and opiates/morphine $(2.0 \mu \mathrm{g} / \mathrm{mL})$. The procedure of the HPTLC method, used for the screening comparison, was as follows: the sample was filtrated; then alkalized with $50 \%(\mathrm{w} / \mathrm{w}) \mathrm{NaOH}$ to $\mathrm{pH} 9-10$. The sample was extracted 3 times with diethylether; dried with sodium sulfate and acidified with $\mathrm{HCl}$ to a $\mathrm{pH} 3-4$; then the extract was evaporated. The HPTLC plates Merck 60 F-254 (Merck, Darmstadt, Germany) and ethylacetate - methanol - ammonium 34:4:2 (v/v) as a mobile phase were used.

\section{Sample preparation}

The real samples of urine and saliva from addicts were extracted and prepared according to the procedure described below.

Extraction of amphetamines and benzodiazepines: The sample was adjusted with $1 \mathrm{M}$ sodium hydroxide to $\mathrm{pH} 9-$ 10 and then shaken for 3 min with ethyl acetate. The water layer was removed after the extraction. The organic layer was shaken with water and the water layer was removed again. The remaining organic layer was shaken with $0.1 \mathrm{M}$ $\mathrm{HCl}$ for 2 minutes and the water layer was separated out and alkalized with $20 \%(\mathrm{v} / \mathrm{v}) \mathrm{Na}_{2} \mathrm{CO}_{3}$. The water phase was reextracted with ethyl acetate and the water layer after reextraction was removed. The organic extract was dried with anhydrous sodium sulphate and organic phase with addition of $0.1 \mathrm{M} \mathrm{HCl}$ in isopropyl alcohol was evaporated in a stream of nitrogen at $25^{\circ} \mathrm{C}$.

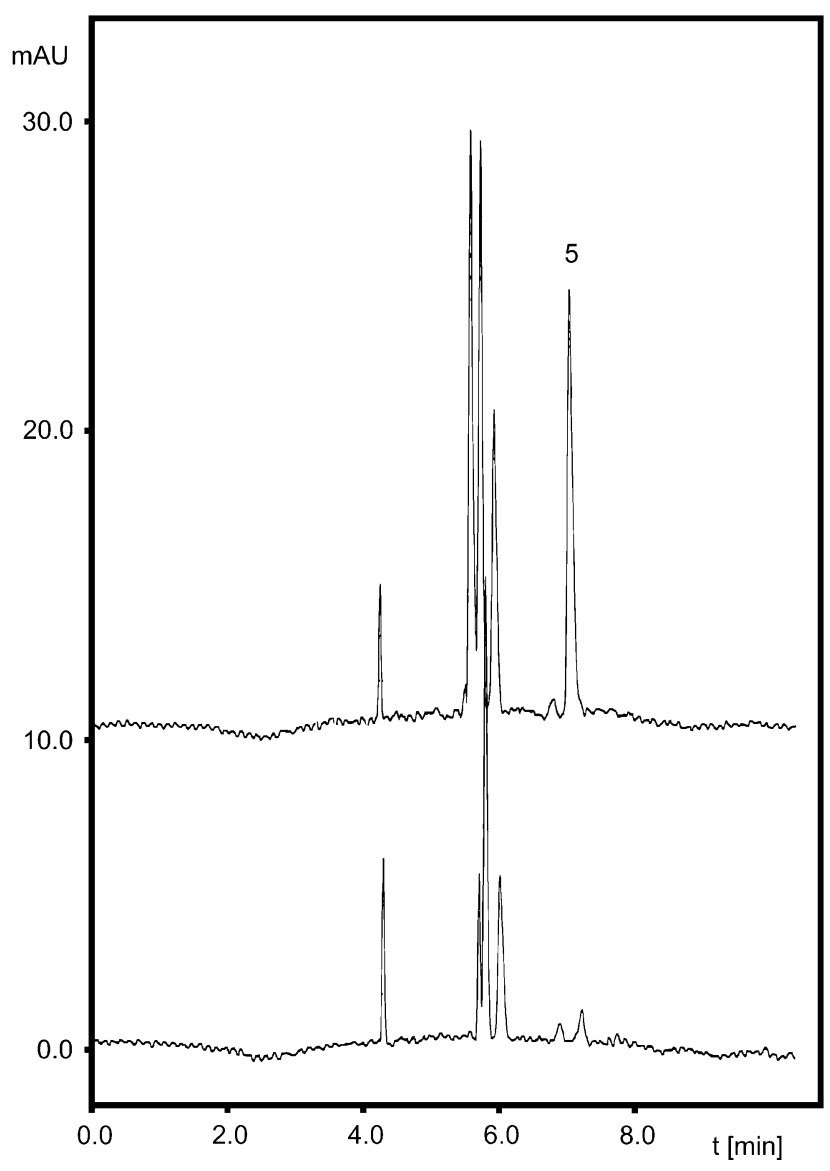

Fig. 3. Electropherograms of urine extract from volunteer with morphine.

BGE $50 \mathrm{mM}$ phosphate-Tris buffer $\mathrm{pH} 2.0$ with $30 \%(\mathrm{v} / \mathrm{v})$ of methanol; separation voltage $30 \mathrm{kV}$. Top electropherogram presents the sample after 6 hours after dosage. Lower electropherogram corresponds to sample immediately after dosage.

5: morphine (MOR)

Extraction of opiates: The sample was adjusted with concentrated $\mathrm{NH}_{4} \mathrm{OH}$ to $\mathrm{pH} 9-10$ and then shaken for 3 min with a mixture of chloroform and isopropyl alcohol $(4: 1, \mathrm{v} / \mathrm{v})$. The water phase was removed after extraction and the organic phase was dried with anhydrous sodium sulphate and organic phase with addition of $0.1 \mathrm{M} \mathrm{HCl}$ in isopropyl alcohol was evaporated in a stream of the nitrogen at $25^{\circ} \mathrm{C}$.

\section{RESULTS AND DISCUSSION}

\section{Separation development}

The examined mixture contained five main groups of frequently misused addictive drugs (amphetamines, benzodiazepines, cannabinoids, cocaine and opiates). All of these analytes were positively charged in acidic background electrolytes. Therefore a very acidic $\mathrm{pH}$ of BGE was chosen. These strong acidic conditions ensure 


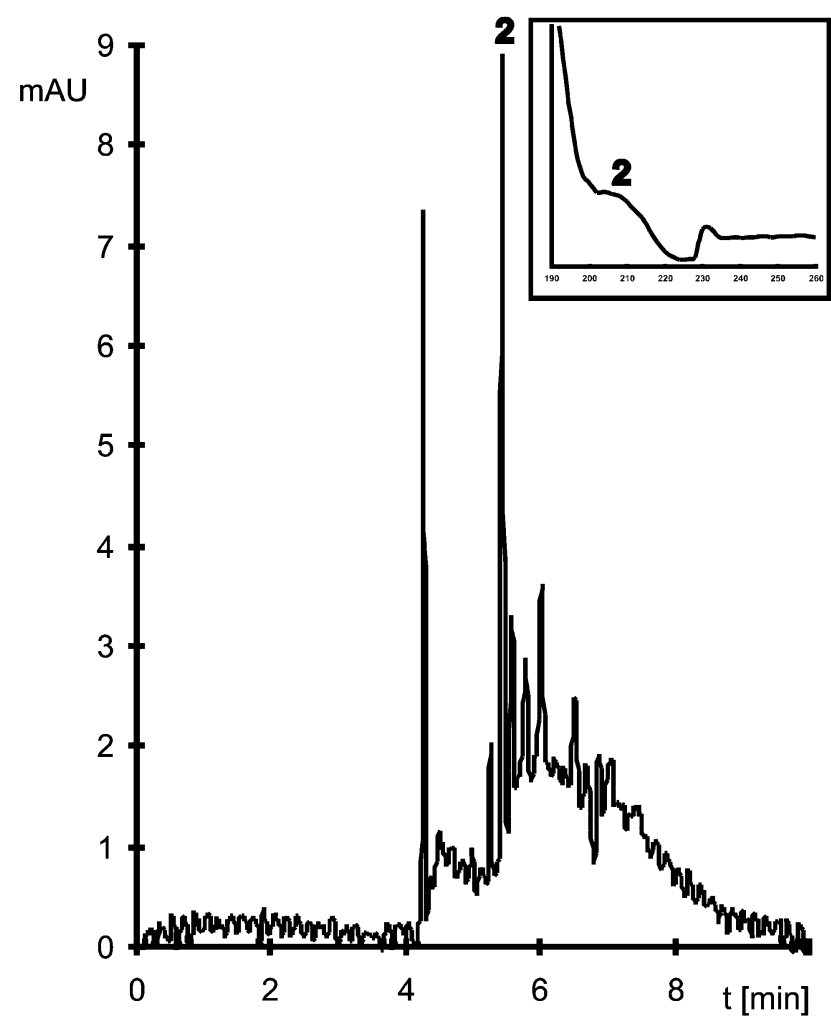

Fig. 4. Electropherogram of urine extract from drug addict with methamphetamine ( 6 hours after dosage).

BGE $50 \mathrm{mM}$ phosphate-Tris buffer $\mathrm{pH} 2.0$ with $30 \%(\mathrm{v} / \mathrm{v})$ of methanol. Separation voltage $30 \mathrm{kV}$.

2: methamphetamine (MET)

protonization and moreover using low $\mathrm{pH}$ of the $\mathrm{BGE}$ and $\mathrm{Tris}^{+}$ions, as coions leads to the suppression of residual electroosmotic flow. In the first experiment $50 \mathrm{mM}$ phosphate Tris $\mathrm{pH} 2.0$ was used for the separation of a standard mixture of drugs. The excellent separation of methamphetamine, amphetamine, cocaine, benzoyleckognine and both benzodiazepines from their metabolites was achieved under these conditions. However the separation of opiates and cocaine was not favourable. Therefore, the addition of native cyclodextrins and organic solvents (methanol, acetonitrile) into the background electrolyte was tested. Native cyclodextrins $(\alpha, \beta, \gamma$ cyclodextrin) were examined as additives for the selectivity; the addition of $\alpha$-cyclodextrin gave the best baseline separation of five morphine analogues. The optimal concentration of $\alpha$-cyclodextrin was $15 \mathrm{mM}$ in $50 \mathrm{mM}$ phosphate Tris $\mathrm{pH}$ 2.0. Unfortunately, separation of 7-aminoflunitrazepam and cocaine under these conditions was lost with this additive.

Furthermore, the influence of methanol and acetonitrile was studied to achieve complete separation of all drugs. Acetonitrile did not allow separating the drugs but methanol can be used. Finally, the addition of $30 \%(\mathrm{v} / \mathrm{v})$ of methanol into the BGE enabled the separation of all studied compounds (Figure 1). The identification of com-

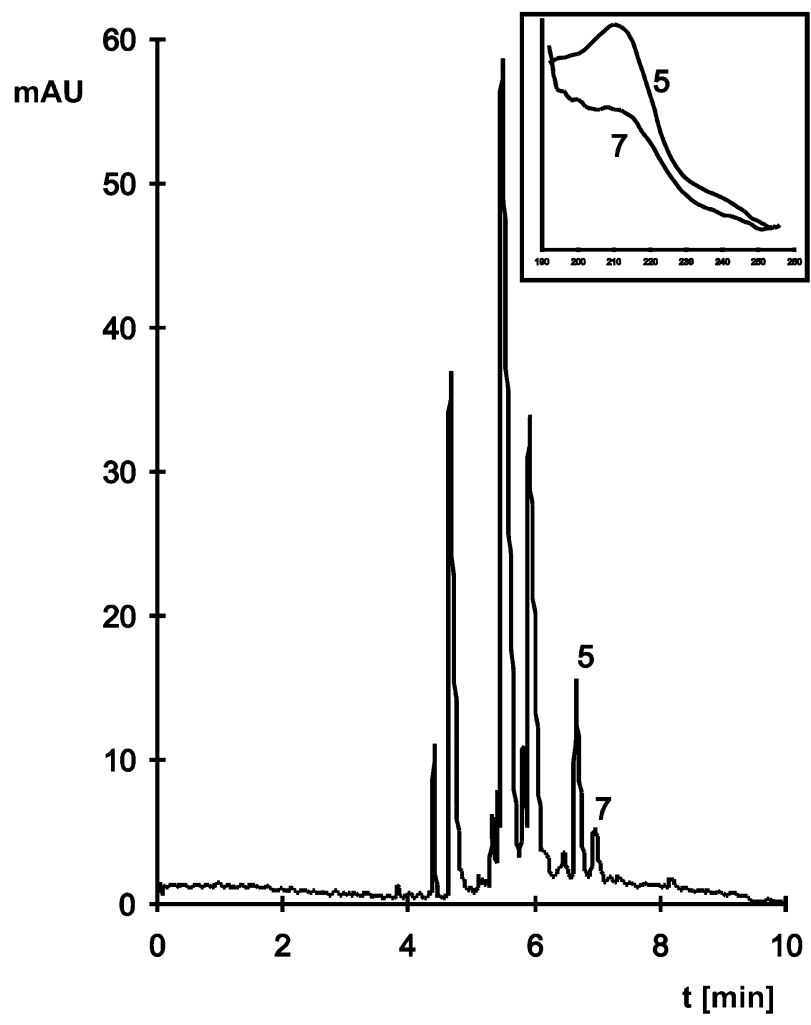

Fig. 5. Electropherogram of urine extract from drug addict with morphine (48 hours after dosage). BGE $50 \mathrm{mM}$ phosphate-Tris buffer $\mathrm{pH} 2.0$ with $30 \%(\mathrm{v} / \mathrm{v})$ of methanol. Separation voltage $30 \mathrm{kV}$.

5: morphine (MOR), 7: 6-monoacetylmorphine

pounds was based on their migration times and characteristic UV spectra. The proposed screening method was partially validated; repeatability, limits of detection and calibration parameters are listed in Table 1; correlation coefficients varied from 0.978 to 0.998 . The precision of peak areas (RSD) did not exceed $3.5 \%$ for intraday assays and $18.6 \%$ for interday assays.

\section{Screening applications}

This simple CE method developed for rapid screening of abused amphetamines, opiates, benzodiazepines and cocaine with their main metabolites was applied to real samples of saliva and urine from drug addicts. The samples of urine and saliva were extracted according to the extraction procedure described in the experimental section. All analyses of real samples were carried out in $50 \mathrm{mM}$ phosphate Tris pH 2.0 with $30 \%$ (v/v) of methanol. Figure 2 presents the electropherogram of saliva extract from an addict after 24 hours of methamphetamine consuming. Saliva as a sample for monitoring drug abuse seems to be suitable because it has a relatively simple matrix (see the Figure 2) and it is easy to sample. On the other hand urine samples from volunteer (Figure 3 ) enable good identification of morphine and its metabolites (in this case six hours after dosage). Figures 4 (6 hours after the meth- 
amphetamine dosage) and Figure 5 (48 hours after the heroin dosage) present electropherograms of extracts of urine samples from drug addicts and prove the possibility of using this method for the real analyses.

The CE method was compared with the HPTLC method and the multicomponent immunochemical screening test QuikScreen ${ }^{\mathrm{TM}}$ on a set of samples from teenage drug abusers in the region of Olomouc, Czech Republic. The results of the drug identification by these screenings are listed in Table 2. Results obtained by CE and HPTLC demonstrate $99.8 \%$ agreement and results from $\mathrm{CE}$ and immunochemical analysis exhibited $95 \%$ correspondence. These results also confirmed the current mode of drug use - the combination of several drugs in order to prolong their effects.

\section{CONCLUSION}

The simple screening capillary zone electrophoresis method that allows recognition of the most abused drugs (amphetamines, opiates, benzodiazepines and cocaine) was developed. The advantages of this CE screening toxicological method include its simplicity with relatively high selectivity for separation and identification of abused drugs, low cost and potential to become the verification tool for immunochemical screenings and the HPTLC screening of abused and/or illegal drugs (agreement of the results was more than $95 \%$ ).

\section{ACKNOWLEDGEMENTS}

Financial support by the Ministry of Education (grant No. MSM 6198959216) is gratefully acknowledged.

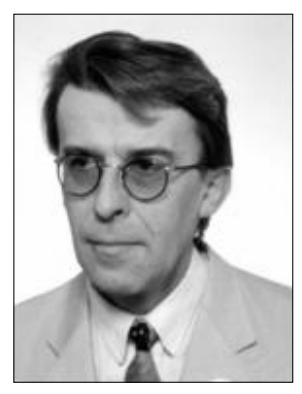

In memoriam. This paper is dedicated to our collegue RNDr. Bretislav Smysl, CSc. who took part in many aspects of our research, who published numerous papers on special cases of poisoning and physical-chemical methods in forensic chemistry.

\section{REFERENCES}

1. Drummer OH. Chromatographic screening techniques in systematic toxicological analysis. J Chromatogr A 1999; 733:27-45.

2. Perezbendito D, Gomezhens A, Gaikwad A. Direct stopped-flow fluorescence polarization immunoassay of abused drugs and their metabolites in urine. Clin Chem 1994; 40:1489-93.

3. George S. Position of immunological techniques in screening in clinical toxicology. Clin Chem Lab Med 2004; 42:1288-1309.

4. Maurer HH. Multi-analyte procedures for screening for and quantification of drugs in blood, plasma, or serum by liquid chroma- tography-single stage or tandem mass spectrometry (LC-MS or LGMS/MS) relevant to clinical and forensic toxicology. Clin Biochemistry 2005; 38:310-8.

5. Maurer HH. Position of chromatographic techniques in screening for detection of drugs or poisons in clinical and forensic toxicology and/or doping control. Clin Chem Lab Med 2004; 42:1310-24.

6. Moore KA, Werner C, Zannelli RM, Levine B, Smith ML. Screening postmortem blood and tissues for nine cases of drugs of abuse using automated microplate immunoassay. Forensic Sci Int 1999; 106:93-102.

7. Crouch DJ, Cheever ML, Andrenyak DM, Kuntz DJ, Loughmiller DL. A comparison of ONTRAK TESTCUP (TM), Abuscreen ONTRAK (R), Abuscreen ONLINE (R), and GC/MS urinalysis test results. J Forensic Sci 1998; 43:35-40.

8. Lai CK, Lee T, Au KM, Chan AYW. Uniform solid-phase extraction procedure for toxicological drug screening in serum and urine by HPLC with photodiode-array detection. Clin Chem 1997; 43:312-25.

9. Nakahara Y. Recent progress of HPLC analysis for drugs of abuse. Jpn J Tox Env Health 1993; 39:369-80.

10. Chen FTA, Evangelista RA. Feasibility studies for simultaneous immunochemical multianalyte drug assay by capillary electrophoresis with laser-induced fluorescence. Clin Chem 1994; 40:1819-22.

11. Boone CM, Waterval JCM, Lingeman H, Ensing K, Underberg WJM. Capillary electrophoresis as a versatile tool for the bioanalysis of drugs - a review. J Pharm Biomed Anal 1999; 20:831-63.

12. Caslavska J, Allemann D, Thormann W. Analysis of urinary drugs of abuse by a multianalyte capillary electrophoretic immunoassay. J Chromatogr A 1999; 838:197-211.

13. Ševčík J, Lemr K, Smysl B, Jirovsky D, Hradil P. One-run chiral separation of methamphetamine and its related metabolites by capillary electrophoresis. J Liq Chromatogr R T 1998; 21:2473-84.

14. Petersen JR, Okorodudu AO, Mohammad A, Payne DA. Capillary electrophoresis and its application in the clinical laboratory. Clin Chim Acta 2003; 330:1-30.

15. Tagliaro F, Bortolotti F. Recent advances in the applications of CE to forensic sciences (2001-2004). Electrophoresis 2006; 27:23143.

16. Brettell TA, Butler JM, Saferstein R. Forensic science. Anal Chem 2005; 77:3839-60.

17. Thormann W, Lurie IS, McCord B, Marti U, Cenni B, Malik N. Advances of capillary electrophoresis in clinical and forensic analysis (1999-2000). Electrophoresis 2001; 22:4216-43.

18. Weinberger R, Lurie IS. Micellar electrokinetic capillary chromatography of illicit drug substances. Anal Chem 1991; 63:823-7.

19. Hilhorst MJ, Somsen GW, de Jong J. Capillary electrokinetic separation techniques for profiling of drugs and related products. Electrophoresis 2001; 22:2542-64.

20. Blanco M, Valverde I. Choice of chiral selector for enantioseparation by capillary electrophoresis. Trends Anal Chem 2003; 22:42839.

21. Tagliaro F, Smith FP. Forensic capillary electrophoresis. Trends Anal Chem 1996; 15:513-25.

22. Fanali S. Enantioselective determination by capillary electrophoresis with cyclodextrins as chiral selectors. J Chromatogr A 2000; 875:89-122.

23. Thormann W, Aebi Y, Lanz M, Caslavska J. Capillary electrophoresis in clinical toxicology. Forensic Sci Int 1998; 92:157-83.

24. Tagliaro F, Turrina S, Pisi P, Smith FP, Marigo M. Determination of illicit and/or abused drugs and compounds of forensic interest in biosamples by capillary electrophoretic/electrokinetic methods. J Chromatogr B 1998; 713:27-49.

25. Anastos N, Barnett NW, Lewis SW. Capillary electrophoresis for forensic drug analysis: A review. Talanta 2005, 67:269-79.

26. Boone CM, Douma JW, Franke JP, de Zeeuw RA, Ensing K. Screening for the presence of drugs in serum and urine using different separation modes of capillary electrophoresis. Forensic. Sci. Int. 2001; 121:89-96. 